\title{
Simulation of heavy metal contamination of fresh water bodies: toxic effects in the catfish and its amelioration with co-contamination with glyphosate
}

\author{
${ }^{1,3}$ OKONKWO, F O; ${ }^{2}$ EJIKE, C E C C
}

\author{
${ }^{I}$ Toxicology Unit, Aiida-4 Medical Consultants, Wuse II, Abuja, Nigeria. \\ ${ }^{2}$ Department of Biochemistry, Michael Okpara University of Agriculture, Umudike, Abia State, Nigeria \\ ${ }^{3}$ Department of Biochemistry, University of Nigeria, Nsukka, Enugu State, Nigeria.
}

\begin{abstract}
The toxic implications of fresh water contamination with zinc in the catfish, Clarias albopunctatus (Lamonte and Nicole, 1927), and the effect of a co-contamination with a sub-lethal dose of glyphosate (Roundup) was studied using the static bioassay model. Thirty six fish were divided into 3 equal groups. Fish in Group 1 were placed in normal tap water, and served as the control group, while fish in Groups 2 and 3 were placed in water contaminated with $\mathrm{ZnSO}_{4}$ and $\mathrm{ZnSO}_{4}+$ glyphosate, respectively. The study lasted for 96 hours (though sampling was done at the $48^{\text {th }}$ hour). Biochemical markers of toxicity were measured and the fish liver and gill histology were studied using standard protocols. The results show that $\mathrm{ZnSO}_{4}$ was significantly toxic to the fish only after 96 hours. Co-contamination of the water with both toxicants was found to ameliorate the toxic effects of $\mathrm{ZnSO}_{4}$ significantly. The metal chelating property of glyphosate may be responsible for the observed attenuation of toxicity in the fish in Group 3.@JASEM
\end{abstract}

Key words: Clarias albopunctatus, glyphosate, metal contamination, toxicity, $\mathrm{ZnSO}_{4}$

Glyphosate is a widely used agrochemical. It is used extensively in agricultural lands and wetlands (Tsui, 2002) where heavy metal contamination is often observed (Tsui et al, 2005). Glyphosate is a well known chelating agent for heavy metals (Subramaniam and Hoggard, 1988) and organic cations (Abate et al, 1999). Glyphosate has been shown to reduce the toxicity and bioavailability of silver, while enhancing the bioavailability of mercury in Ceriodaphnia dubia (Tsui et al, 2005). Surfactants used in the formulation of commercial glyphosate (for example, Roundup) have been implicated in the enhancement of bioaccumulation of metals in organisms (Dennis et al, 1997). The major surfactant in Roundup is polyoxyethylamine (POEA).

Roundup used by farmers in the fields may leach into fresh water ponds as aerial drift or as run-offs. We reported recently, that the toxic effect of sub-lethal concentrations of Roundup on Clarias albupunctatus (Lamonte and Nicole, 1927) was both dose dependent and time dependent (Okonkwo et al., 2010). Concentrations of zinc and sulphide ions were also found to range from $49-65 \mathrm{mg} / \mathrm{L}$ and $0.86-$ $1.21 \mathrm{mg} / \mathrm{L}$, respectively, in fresh water ponds surrounding farmlands in Umueje, an agrarian community in Anambra state of Nigeria (Okonkwo, unpublished laboratory data).

Given the reported toxicity of Roundup and heavy metals in fish, and the heavy metal chelating ability of glyphosate, this study seeks to examine the toxic implications of fresh water contamination with zinc and to evaluate the effect of a co-contamination with a sub-lethal dose of Roundup, using the fresh water catfish Clarias albopunctatus (Lamonte and Nicole, 1927) in a static bioassay model.

\section{MATERIALS AND METHODS}

Fish: Clarias albopunctatus (Lamonte and Nichole, 1927), average weight $43 \mathrm{~g}$, were purchased from a commercial farm in Agbor, Delta State, Nigeria. Using FAO fish transit tanks, the fish were transported to the Wet Laboratory where the study was executed. Upon arrival, flush prophylactic treatment was administered to the fish using potassium tetraoxomanganate (VI) $\left(\mathrm{KMnO}_{4}\right)(1 \%)$. The fish were rinsed in tap water after two minutes and acclimatized to the wet laboratory for 7 days. Water and feed were changed daily at $0800 \mathrm{hrs}$ throughout the duration of the study.

Experimental Design: A total of 36 fish were used for the study. The fish were divided into 3 groups of 12 fish each and treated as follows: Group 1 (control) was exposed to tap water only; while Groups 2 and 3 were exposed to 50ppm $\mathrm{ZnSO}_{4}$ and $5 \mathrm{ppm}$ Roundup + $50 \mathrm{ppm} \mathrm{ZnSO}_{4}$ respectively. The static bioassay method was adopted since it guarantees the maintenance of the toxicant levels and the avoidance of the accumulation of waste products during the study period. The study lasted for $96 \mathrm{hrs}$ (though sampling was done at the 48th and 96th hour). Six fish were sampled per group, per time. The fish were bled exhaustively by cardiac puncture, using disposable hypodermic syringes and the blood placed in clean sample containers. The blood samples were allowed to clot at ambient temperature and thereafter sera were separated by centrifugation and used for the biochemical analysis. Portions of the livers and gills of the fish were removed immediately after blood collection at the 96th hour and prepared for histological studies.

Assays and determinations: Total and Conjugated Bilirubin Determinations in Serum: The method described by Jendrassik and Grof (1938) was used for the determination of both total and conjugated bilirubin in serum. Conjugated bilirubin reacts with 


\section{Simulation of heavy metal contamination....}

diazonitized sulphonic acid in an alkaline medium to form a blue colored complex. Total bilirubin is determined in the presence of caffeine which releases albumin-bound bilirubibin in the reaction with diazonitized sulphonic acid.

Serum Alkaline Phosphatase (ALP) Assay: Serum ALP was assayed by the method of Rec (1972). Serum alkaline phosphatase hydrolyzes a colorless substrate of phenolphthalein monophosphate giving rise to phosphoric acid and phenolphthalein which, at alkaline $\mathrm{pH}$, turns pink and can be measured spectrophotometrically.

Serum Aspartate Aminotransferase (AST) Assay: Serum AST was assayed by the method of Reitman and Frankel (1957). AST catalyzes the reaction between $\alpha$-oxoglutarate and L-aspartate to give Lglutamate and oxaloacetate. The AST in the sample is measured by monitoring the concentration of oxaloacetate hydrazone formed with 2,4dinitrophenylhydrazine.

Serum Alanine Aminotransferase (ALT) Assay: Serum ALT was assayed by the method of Reitman and Frankel (1957). ALT catalyses the reaction between $\alpha$-oxoglutarate and $\mathrm{L}$-alanine to give $\mathrm{L}$ glutamate and pyruvate. The concentration of ALT is measured by monitoring the concentration of pyruvate hydrazone formed with 2,4dinitrophenylhydrazine.

Serum Urea Determination: Urea in serum was estimated by the method of Searcy et al. (1967). The principle is based on the hydrolysis of urea by urease, to give ammonia and carbon dioxide. The ammonia so formed reacts with alkaline hypochloride and sodium salicylate in the presence of nitroprusside to form a coloured chromophore, the intensity (measured spectrophotometrically) of which is proportional to the concentration of urea in the sample.

Serum Creatinine Determination: Serum creatinine was determined using the method of Newman and Price (1999). The principle is based on the production of a red colored complex by the reaction between creatinine and picric acid in alkaline solution to form a red colored complex. The intensity of the colour is spectrophotometrically measured, and is proportional to the concentration of creatinine in the sample.

Histology: Liver and gill tissues were fixed in $10 \%$ formal saline for 24 hours. Thereafter they were washed and dehydrated in grades of ethanol, cleared in xylene and then infiltrated and embedded in paraffin. Sections of the embedded tissues $(4-5 \mu \mathrm{m}$ each) were cut using an ultramicrotome, stained with hematoxylin and eosin, and their photomicrographs taken at $\times 10$ magnification.

Statistical analysis: Descriptive statistics was carried out and the results presented as mean \pm standard deviation. Differences between means were separated using one way ANOVA with the significant threshold employed at $P \leq 0.05$. Data analyses were done using SPSS version 16.0 (SPSS Inc., Chicago IL).

\section{RESULTS AND DISCUSSION}

The serum levels of both total and conjugated bilirubin in the group treated with $\mathrm{ZnSO}_{4}$ were statistically similar $(p>0.05)$ to the control group. After 96 hours of exposure, the serum concentrations of both total and conjugated bilirubin were significantly higher $(\mathrm{p}<0.05)$ than those of the control group. Irrespective of duration, the serum levels of both total and conjugated bilirubin in the group treated with both toxicants were significantly $(\mathrm{p}<0.05)$ lower than the values recorded in the $\mathrm{ZnSO}_{4}$ - only group (after 96 hours) but statistically similar ( $p>0.05$ ) to the values got for the control group (Fig. $1)$.

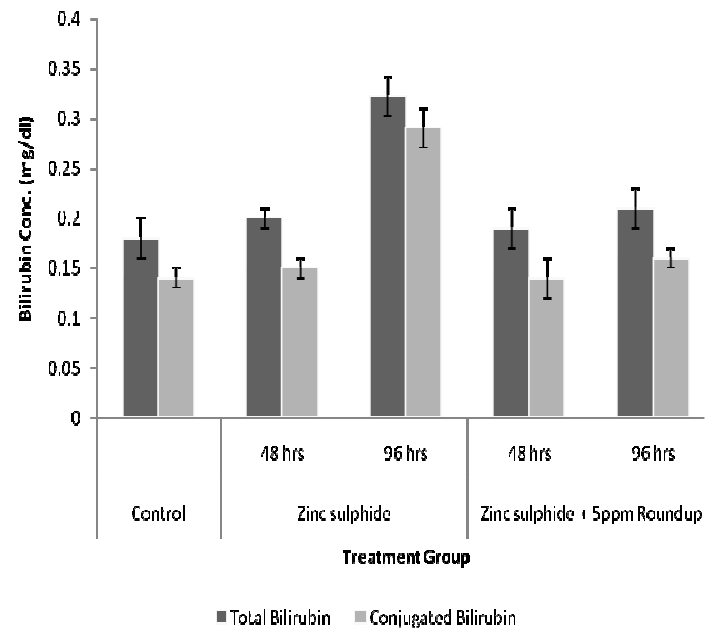

Fig. 1: Concentrations of total and conjugated bilirubin in the serum of fish exposed to the toxicants

Figure 2 shows that the serum alkaline phosphatase concentrations of the fish in all the test groups and for both durations of exposure (except at 96 hours in group 2) were not (each) statistically different ( $>0.05)$ from values recorded for the control group. Serum AST concentrations in the two test groups irrespective of duration were statistically similar ( $p>0.05)$ to those of the control group. However, serum ALT concentrations in the test groups were significantly higher $(\mathrm{p}<0.05)$ than those of the control group only after 96 hours of exposure. 


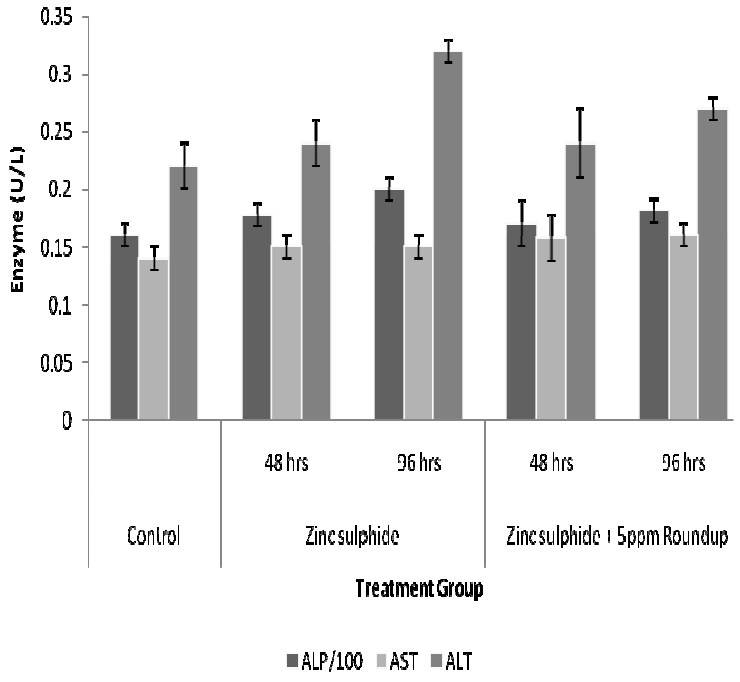

Fig. 2: Serum concentrations of some liver enzymes of fish exposed to the toxicants

From Figure 3, it is seen that both serum urea and creatinine concentrations were significantly higher $(\mathrm{p}<0.05)$ than values recorded for the control group only in the $\mathrm{ZnSO}_{4}$-only group exposed for 96 hours. All the other values were not significantly different ( $p>0.05)$ from values recorded for the control group. A section of the liver from fish in the control group is shown in Figure 4a. Normal liver histology, characterized by inconspicuous lobulation and cords of hepatocytes separated by sinusoids, is seen. The hepatocytes (shaped polygonally) have centrally located vesicular nuclei. Figure $4 \mathrm{~b}$ shows a distortion of the lobular architecture of the liver of fish in the group treated with $\mathrm{ZnSO}_{4}$. Some of the hepatocytes in the centrilobular areas have mild granular cytoplasm and pyknotic nuclei. From Figure $4 \mathrm{c}$, a less severe distortion of the lobular architecture of the hepatocytes of fish in the group treated with both toxicants is seen. Pyknosis in the centrolobular area and vacuolation in the cytoplasm are clearly less severe than what is found in the group exposed to only $\mathrm{ZnSO}_{4}$. Figure 5a shows a section of fish gill from the control group. It shows a normal appearance of primary lamellar epithelium, choride cells and pillar cells. Figure 5b shows an abnormal and irregular thickening of the primary lamellar epithelium of the gills of fish exposed to $\mathrm{ZnSO}_{4}$. A similar but less severe distortion in the appearance of the gills is seen in Figure 5c.

The liver is responsible for the transformation of foreign substances (xenobiotics), a process that aims to make such xenobiotics water soluble and hence amenable to excretion. It is therefore, naturally, subject to potential damage by a wide array of pharmaceutical and environmental chemicals that find their way into the system.

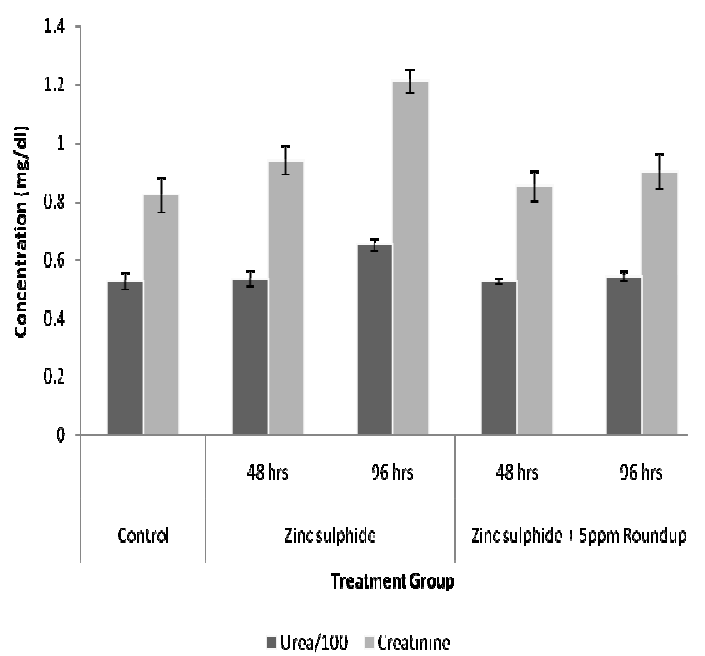

Fig. 3: Serum concentrations of urea and creatinine in fish exposed to the toxicants

Thus, liver function tests are surrogates for the assessment of toxicity in animals. Elevations in serum total and conjugated bilirubin concentrations are attributable to liver and/or biliary tract disease (Iyanagi and Accoucheur, 1998), while elevations in ALT and AST concentrations in serum are usually due to disruption of hepatic cells as a result of necrosis or altered membrane permeability, and elevations in serum ALP concentration is often due to cholestasis (Ejike et al., 2008). The exposure of the fish in Group 2 to $\mathrm{ZnSO}_{4}$ resulted in significant toxicity only after 96 hours as shown by the results of the liver function tests. Such increase in markers of toxicity may be as a result of stepped-up transamination in attempt to cope with the energy crisis during exposure to stress as a result of a toxicant (Philips and Rajasree, 1996; Okonkwo et al.,2010). The production of lipolytic mitochondrial enzymes (in response to the presence of toxicants like phorate and carbaryl) that dissolve cell membranes, lysosomal membranes and other hepatocellular organelles, thereby releasing liver enzymes into the blood is also believed to be one of the ways through which elevations in liver enzymes in serum occur (Jyothi and Narayan, 1999). The elevations in serum levels of total bilirubin and conjugated bilirubin in the fish in Group 2 after 96 hours may be subsequent to the disruption of the hepatic architecture by zinc ions such that the conjugation of bilirubin and excretion of bilirubin is altered.

It is however interesting that the toxic effects of $\mathrm{ZnSO}_{4}$ is attenuated in the group that were treated with both $\mathrm{ZnSO} 4$ and glyphosate (Roundup) as toxicants. In the said group, serum concentrations of the assayed enzymes were similar to the values recorded for the control group, even after 96 hours. This is despite our earlier finding that Roundup singly, at 5ppm or higher concentrations, induced 


\section{Simulation of heavy metal contamination....}

significant liver toxicity after 96 hours in fish (Okonkwo et al., 2010). Glyphosate is a known chelating agent for heavy metals and organic cations (Subramaniam and Hoggard, 1988; Abate et al, 1999). Glyphosate anion has three chemical groups amine, carboxylate and phosphonate - which can strongly bind to cations, especially the hard transition metals; thus conferring on it its chelating ability. This chelation may explain the absence of toxicity in the fish treated with both toxicants, even after 96 hours when each ordinarily showed significant signs of toxicity. The data from the liver function tests are corroborated by the histomorphologic changes observed in the liver sections of the test fish, relative to the control fish. The sections show a clear disruption of the lobular architecture, distortion, vacuolation and condensation in the liver in the $\mathrm{ZnSO}_{4}$ group, relative to the control group, and an amelioration of such architectural disruption in the $\mathrm{ZnSO}_{4} /$ Roundup group. Urea is a product of the deamination of glucogenic amino acids in the liver typically in the alanine cycle. Creatinine in serum is a metabolite of muscle creatinine. Both serum urea and creatinine concentrations are usually constant because both are easily excreted by the kidneys. Elevated levels of both serum urea and creatinine concentrations therefore indicates an impairment in renal function (Loeb, 1991). The elevations in the concentrations of urea and creatinine in the serum of fish exposed to $\mathrm{ZnSO}_{4}$ after 96 hours is therefore indicative of diminished renal function as a result of kidney damage. On the other hand, the absence of such significant elevations in the $\mathrm{ZnSO}_{4}$ /Roundup group suggests a preservation of renal function by the co-administration of the toxicants - an effect that is possibly attributable to the chelating properties of glyphosate.

In fish, the gills provide a large interface between the external and internal environments and as such are the first organs to get in contact with xenobiotics (Jiraungkoorskul et al., 2003). The gills are particularly sensitive to changes in environmental conditions and perform such vital functions as ion osmoregulation, gas exchange and nitrogen excretion. Disruptive changes in gill epithelia are considered good indicators of tissue lesions caused by chemical pollutants (Gingerich, 1982). A severe destruction of the gills by the toxicant is seen in the histologic sections of fish in the Group 2, while the sections from the fish in Group 3 show a slight reduction in the disruption of the gill architecture. The patterns of disruption of the gills corroborate the patterns observed for the liver toxicity and lend credence to the ameliorative potential of Roundup with respect to zinc ion toxicity.

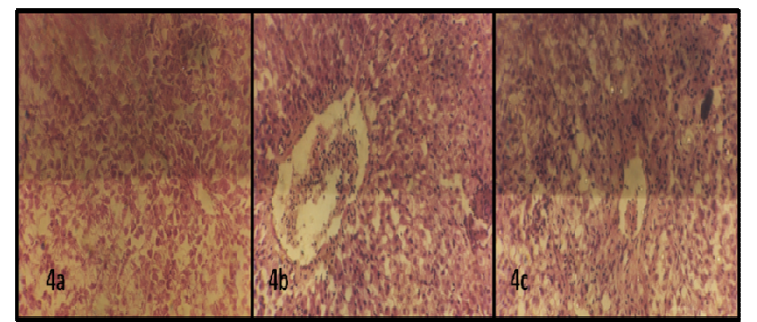

Fig. 4: Histology of the liver of fish in the control group (4a) and the test groups treated with zinc sulphide (4b) and zinc sulphide + 5 ppm Roundup (4c) as toxicants

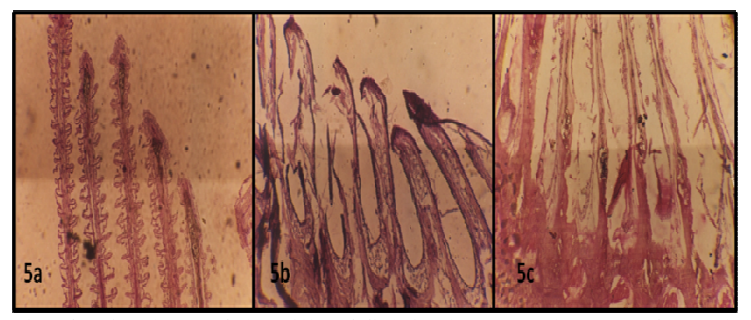

Fig. 5: Histology of the gills of fish in the control group (5a) and the test groups treated with zinc sulphide (5b) and zinc sulphide + $5 \mathrm{ppm}$ Roundup (5c) as toxicants

The exposure of Clarias albopunctatus to water contaminated with $\mathrm{ZnSO}_{4}$ was found to be toxic to the fish. This is worrisome as the water bodies sampled around farmlands in Umueje were found to contain considerably high concentrations of both zinc and sulphide ions (Okonkwo, unpublished laboratory data). Though this contamination may have very severe negative consequences for the fish population in the water bodies surrounding the farmlands, and in turn affect the source of animal proteins for human populations (largely peasant farmers) inhabiting such areas, it is relieving to observe that the toxicity from this metal ion is significantly ameliorated by cocontamination with Roundup, a widely used herbicide in the mentioned community. Further studies are required to appreciate better this observed chelation of zinc ions by Roundup with a view to exploiting it in environmental biotechnology, with respect to the remediation of heavy metal or herbicide polluted fresh water bodies.

\section{REFERENCES}

Abate, L., De Stefano, C., Sammartano, S. (1999). Binding of glyphosate by open-chain polyammonium cations. Environ. Toxicol. Chem. 18: 2131-2137.

Dennis, J.L., Mutwakil, M.H.A.Z., Lave, K.C.and De Pomerai, D.I. ( 1997). Effects of metal ions in combination with a non-ionic surfactant on stress responses in a transgenic nematode. Aquatic Toxicol. 40: $37-50$.

Ejike, C.E.C.C., Alumanah, E.O., Ezeanyika, L.U.S., Ngene, A.A. and Ojefua, E.E. (2008). Antibiotics administration and its possible liver damage. BioResearch; 6: 351-354 
Simulation of heavy metal contamination....

Gingerich, W.H. (1982). Hepatic toxicology of fishes. In: Weber, L.J., Ed. Aquatic Toxicology. Raven Press, New York. pp 55-105.

Iyanagi, E.Y. and Accoucheur, S. (1998). Biochemical and molecular disorders of bilirubin metabolism. Biochem. Biophys. Acta 1407: 173-184

Jendrassik, J. and Grof, P. (1938). Vereinfachte photometrische methoden zur bestimmung des blutbilirubin. Biochem. Z.; 297: 81-89.

Jiraungkoorskul, W., Upathan, E.S., Kruatrachue, M., Sahaphong, S., Vichasri-Grams, S. and Pokethitiyook, P. (2003). Biochemical and histophatholocal effects of glyphosate herbicide on Nile Tilapia Oreachronis niloticus. Environ. Toxicol.; 18: 260-267.

Jyothi, B. and Narayan, G. (1999). Certain pesticide induced carbohydrate metabolic disorders in the serum of fresh water fish, Clarias batrachus (Linn) Food Chem. Toxicol.; 37: 417-421.

Loeb S (1991) Clinical laboratory test: values and implications. Springhouse Corporation, Pennsylvania. pp 124-128.

Newman, D.J. and Price, C.P. (1999). Renal function and nitrogen metabolites. In: Burtis, C.A. and Ashwood, E.R. (Eds) Tietz Texbook of Clinical Chemistry. $3^{\text {rd }}$ Edition, WB Saunders Company, Philadelphia, pp 1204.

Okonkwo, F.O., Ejike, C.E.C.C., Anoka, A.N. and Onwurah, I.N.E. (2010) Toxicity in the catfish, Clarias albopunctatus (Lamonte and Nichole 1927), exposed to sub-lethal concentrations of Roundup. Trop. J. Biomed. Allied Sci. Res.; 5: 500-507
Philips, G.H. and Rajasree, B.H. (1996). Action of cypermethrin on tissue transamination during nitrogen metabolism in Cyprinus carpio. Ecotoxicol. Environ. Safety; 34: 174-179.

Rec, G.S. (1972). A colorimetric method for the estimation of alkaline phosphatase. J. Clin. Chem. Clin. Biochem.; 10: 18

Reitman, S. and Frankel, S. (1957). A colorimetric method for the determination of serum oxaloacetic and glutamic pyruvic transaminases. Am. J. Clin. Pathol.; 28: 56-63.

Searcy, R.L., Reardon, J.E. and Foreman, J.A. (1967). A new photometric method for serum urea nitrogen determination. Am. J. Med. Technol.; 33: 15-20.

Subramaniam, V. and Hoggard, P.E. ( 1988). Metal complexes of glyphosate. J. Agric. Food Chem.; 36: 1326-1329.

Tsui, M.T.K. ( 2002). Aquatic toxicity and environmental fate of glyphosate-based herbicides. M. Phil thesis. The Chinese University of Hong Kong, Hong Kong SAR, China.

Tsui, M.T.K., Wang, W. and Chu, L.M. ( 2005). Influence of glyphosate and its formulation ( Roundup) on the toxicity and bioavailabilty of metals to Ceriodaphnia dubia. Environ. Pollution; 138: 5968. 